\title{
Consumer Perception and Attitude towards the Visual Elements in Social Campaign Advertisement
}

\author{
${ }^{1}$ Ashish Sharma, ${ }^{2}$ Ambudi Bhosle, ${ }^{3}$ Brijesh Chaudhary \\ ${ }^{1,3}$ (Asst. Prof. in Management Department In Gicts Group Of Institutions, Gwalior, India) \\ ${ }^{2}$ (Asst. Prof. in Humanities Department in Madhav Institute Of Technology And Science (MITS), Gwalior, \\ India)
}

\begin{abstract}
Abstarct : This research paper tries to explore and describe consumer's attitude and perception towards the visual elements in social advertising campaign. The literature review concentrates on key areas of consumer behaviour, the role of perception in communication and the role of different image contents and elements in social advertising. We have used semi structured questionnaire and two focus-groups to obtain and analyse the feedback and observations of people regarding visual advertisements. Following from these are the results and discussion that focus on four key areas: perception towards social advertising; attention and interest; congruence; and authorial intent and reader response. Results indicate that perception towards image of social advertisements differed quite significantly between the male and the female respondents. Congruence was found to be highly subjective, and although the respondents showed great approval of an advertisement As a result of contrasting shock element and sexual element in social advertisement. The researcher came to the conclusion that these elements are the most effective in capturing attention and interest. The study concludes with a discussion of the main implications of the research and with forwarding of suggestions for further research.

Keywords: Social Advertising, Visual elements, Consumer Behaviour.
\end{abstract}

\section{Introduction}

The importance of advertising is constantly growing in today's world. The media of social message have its great impact all around, similarly advertising, which use media as its tools, is a persuasive and powerful force that is shaping behavior and attitude in society. Social advertisements are continuously trying to convince people for social cause such as leaving the drug, quit smoking or stop violence etc. Every person in the world is consumer of social campaigns. Basically social advertisements are developed by different government or nongovernment organisations. Intentions behind social advertisements are to break down the practice of undesired behavior in society or to stimulate the desirable practices towards environment, people and surroundings. (Bloom and Novelli, 1981).

"The target of social marketing messages often aim to internal behavior influences on the individual" (Kotler, 2005).

This particular chapter focuses on the visual advertising of social campaigns and consumer's attitude and perceptions about it. And also identifies the research aim, objectives, and rationale of the research.

1.1 Study aims: The study aims to evaluate the impact of social advertising campaigns on consumers' attitude through analysis and critical evaluation of visual impact.

1.2 Study objectives:

1. To conduct an In-depth analysis of, how social campaigns' visuals make their place in consumers' mind? And consumers' perception and attitude towards the visual elements of social campaign adverts- Consumer perspective.

2. To critically evaluate the visual power of social campaigns advertisements.

3. To critically evaluate consumer perception of various social campaign.

4. To critically compare the effectiveness of social campaigns on male and female.

\subsection{Rationale for Studies:}

Almost every person takes interest in advertisements these days. Consumers are exposed to hundreds of advertisements every day. In our total life span, we spend almost one and a half year watching TV-ads (Lutz, 1990). Advertising is the subject which seems to be riddled with inscrutability and perceptible contradictions. Advertising has emerged into an immensely composite form of communication, with literally many different ways for the consumer to get a message from business. Social campaigning is one of the forms of advertising.

There were numerous reasons behind the proposal of this research. Firstly, it will be immensely important to students, research scholars, advertising professionals and campaigners to obtain a proper insight 
into the reaction and attitude of targeted customers given to the art of creating advertising of social campaigns. There are also expectations that information and comprehension presented in this research will meet many practical implications because there are very few research had been conducted in the similar objectives. Secondly, with the social campaigning advertising companies are in dilemma to process the most accurate way to create an effective social advertisement to avoid risks and time lapse and enhance its effectiveness, improve mass awareness. These are the reasons that is why researcher believes that there is a need to understand the endconsumers' attitude and perception about different visual rhetoric that they consider the most effective. Thirdly, instead of wasting valuable money on less effective advertising, organization should invest money on appropriate advertising that really moves the consumers emotionally and the end-customers think is most appealing and impactful in terms of social awareness and value generation.

"Creating a campaign is a creative and a technical process where scope of art and science come together" (Campaignstrategy, 2011). In socially derived marketing, elements of visual language come together with the scientific research results of social science and knowledge. This thesis will mainly focus on social and information campaigns developed by any organization fighting for social issues such as human rights, environmental issues, poverty, violence, public health and security, etc. Social marketing is defined as the "design, implementation, and control of programs seeking to increase the acceptability of a social idea in a target group" (Kotler and Armstrong, 1989). Social campaigning is the field which is a type of non-profit marketing, which includes public health campaigns (e.g., those to reduce smoking, alcoholism, drug abuse, overeating); environmental campaigns (e.g., wilderness protection, recycling) and other campaigns (e.g., human rights, social equality) - (Kotler and Zaltman, 1971).

In our daily life, we see continuous campaigning around us which try to persuade people to quit smoking, to discard drugs, to ignore alcohol, to practice safer sex or to educate. The basic aim of these campaigns can be on the one practice to break down the undesired activities, as for example activities which harm the environment (global warming, pollution), harm health (drinking, smoking, drug addiction) or have an effect on other in society (violence, sexual abuse). On the other side behavior can be influenced which is enviable (don't drink \& drive, use condoms, keep the city clean) for the own life or the society. A social campaign is a broad attempt to converse ideas and practices with mass media and interpersonal communicating.

\subsection{Persuasion}

Persuasion has become very important in advertising. A main reason is that market competitor found it very easy to erode any functional or value advantage attached with a product. Companies are trying to reactive wide neglected manners of reaching to customers. Persuasion is to change someone's attitude, perception or behavior as a communication goal. "Persuasion is a symbolic process in which communicators try to convince other people to change their attitudes or behavior regarding an issue through the transmission of a message, in an atmosphere of free choice" (Perloff, 2003). As we think about communication as a way of persuasion tool and its social impact on general people's life there is one more word can come to mind, is Propaganda. Persuasion is very effective element for marketing. Persuasion occurs in interpersonal relations or in mediated settings and in the noble situation it allows a free flow of information in the direction of two-way. Persuasion is positive process of communication that can produce valuable results.

Figure 2:

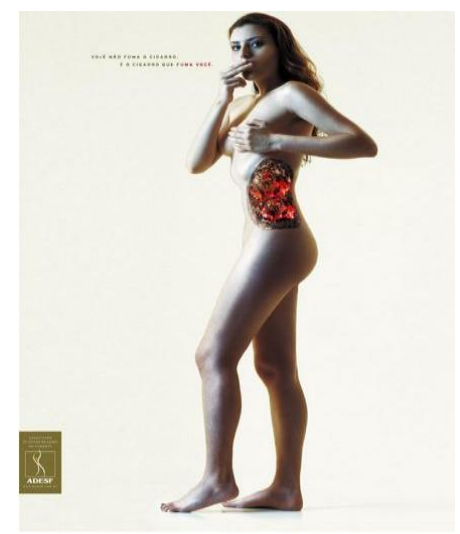

figure 1: You don't smoke cigarette, cigarette smokes you.

This poster gives a message to people, which is basically visual persuasion. Image tells, you don't smoke cigarette, cigarette smokes you. The girl illustrated shows a gesture of smoking, inside her body, her internal organs burn like the blaze of a cigarette. 


\section{Outline of Chapters}

This research study is divided in five different chapters providing an overview of the research undertaken. The very first chapter of this research discuss about the aim and objectives, visual persuasion as a whole and with comparison with other aspects of communication and a brief introduction to the social campaigns and advertising in the social campaigns.

Second chapter consists of various academic literature reviews spoke about visual processing, persuasion in advertising and processing fluency to set up the theoretical framework for present research which has helped the researcher to study, understand and apply the literary work of other authors, scholars and professionals to justify the research undertaken. The literature review underlines the emotional and experimental nature of visual advertising in social campaigns. It also highlights the attitude and perception created by consumers affected by visual persuasion.

Third chapter discusses in detail about the research methodology used while conducting the research. Fourth chapter focuses on research findings and analysis. It presents the results of each study. Results for all studies will comprise detailed analysis of qualitative data which concern to experimental processing of visual persuasion.

Fifth chapter discusses about the conclusion and recommendations. It includes interpretation and discussion of the key finding along with the discussion of the theoretical and practical connotation of the results. Fifth chapter will also give some suggestions for future research and to finish with the limitations of the research.

\section{Literature review}

This chapter discusses the aims and objectives of the research, importance and background of the social advertising and visual persuasion. This chapter focuses on the various literatures related to the visual persuasion, social advertising and consumers' attitude and perception towards it. These literatures have been published in various books, journals and articles. Because of the uniqueness of the research, researcher felt the limitations to source literature which are directly or indirectly related to the research nature and problem. Though the literatures used in this section develops a wide understanding of various advertising phenomenon in the recent decades.

Now consider an image with no words that advertises a social cause of no-smoking. There is a picture of cigarette litter box stuck on the wall. This box has a front of transparent plastic sheet with the picture of lungs. This lung's picture has such transparency that all the used cigarette filters inside are visible through it. Thus at first glance, the litter box seems like lungs filled with burnt cigarette. It doesn't seem like a pleasant picture. Perhaps reading this description can make you think about it. Now you have read it you can build an image in your mind. It can stir up some positive feelings in your sense. Now you have encountered the image verbally, but the main point is that, have you come across the image visually? The experience appears to have been immediate and it could have given a long lasting impact with more emotional and stronger effect. The image which is just described above is a social campaign figure "no smoking" in Appendix 1 (advertisement 1).

What makes this image an impressive social advertisement is the unusual and unexpected way of implication of its objective. It could have made in a straight forward way with the cancer affected lungs coupled with some phrase such as "smoking can cause cancer". The image has two elements in it, one is lung picture and other is litter box. These two have no obvious relation to each other and then lets the viewer's mind experience those two elements together and make appropriate and meaningful connection on its own (as mind does it naturally).

\subsection{Effectiveness of a Social Campaign}

The campaign's effectiveness and attitude of consumers and perceptions towards it, are measured by focus groups and semi-structured questionnaire. On one hand the campaign point at its communicative working, which refers to the variety of the communication means (How many people received the message?), the approval and status of the communication (Did people like it?) and the relocation of the message (Did people understand the message?). On the other hand it looks at its effects on knowledge of people (Do people know more about the subject now?), attitude (Did their attitude change referring to the topic?) and their behaviour (Did a real behavior change take place?). An actual behaviour change can frequently not actually be measured but rather the people's intention to alter their behavior in question is measured. Further it is checked if the people have developed a requirement for more information referring to the topic of campaign or if the information provided by the campaign is adequate.

\subsection{Visual processing}

Almost $75 \%$ of whole information processed in brain is basically visua. There are some extensive researches has been done by Anne Marie Barry (Barry, 1997; Berry, 2005) in visual processing and the 
implication of how the visual system functions for people in modern times trying to navigate the visual environment. At subconscious level, minds don't make a distinction between real and the information in visual form transmitted to us from bill-boards, newspapers, phone screen, computer screen or any other way. Our mind is like a processor which process information avidly that is always looking for meaning and understanding. Our mind has a tendency to fill in unfinished visual narratives automatically such as movies and commercials that go from one scene to another while leaving the large gaps in narrative.

Barry (1997) states that the typical high school student in late $20^{\text {th }}$ century had been exposed to 350,000 condensed stories containing basic problems and solutions communicated with much idealized emotion-educing images all of which make life seem very easy. Barry (1997) also warns about heavy volume of exposure towards visual adverts may be productive when we know about how the information is processed by the visual system. Experience is the root of visual processing and visual processing stands between our self and the world with the help of these experiences. Advertising practitioners such as Phillips et al. (2002) think that these connections are in existence and have tried to merge their communications with positive experience, which will resound with our unconscious mind (Schroeder, 2002).

Schroeder (2002) explains how market is full of visual imagery trying to persuade; brands are portrayed extensively with the use of images and a number of products are made in such a way to correspond visually. "The dominance of visual imagery does not necessarily make for visual literate consumers. Visual consumption often involves mere looking without comprehension, gazing without knowledge, and watching without engagement" (Schroeder, 2002: p.11).

\subsubsection{Advantages of visual advertisements:}

Unlike visual processing, verbal processing is mostly limited in language center within higher cortex. Childers and Jiang (2008) differentiate the two systems and explain that verbal process takes longer time to be processed, whereas visual process obtains an immediate response from mind. Thus, in the situations of advertising research that make naturalistic conditions, in which participants doesn't wish to direct all of their resources to process the persuasive stimulus. It is rational to expect that because the brain processes visual information easily.

Basically results explain the notion that visual advertisements are more prominent and more reliable, because mind is able to get more information while processing fewer resources.

In modern age consumers may not be practiced as visual processors to handle successfully with There is some research in advertising which is done by Hung and Wyer (2008), in which there were two conditions for participants. Either they were allowed to use their full mental capacity to process the advertisements or in condition of mental restrictions where they had to memorize a 12 digit number prior to process the advertisement. This experiment presented a solution for pretended comprised verbal, visual or combination of both. Advertisement was rated based on participants' own perceptions that (i) advertisements are generally full of information or (ii) information is intentionally exaggerated in advertisements.

Result showed that when the advertisements were shown in a pure visual form without any cognitive load, advertisements were rated most effective (with more information) than in other situation. Contrarily, when these advertisements were shown in a verbal format, participants rated them as desperately exaggerated huge number of visually persuading advertisements to which they are exposed over life time. In addition, in comparison of how visual and verbal advertisements are processed, visual advertisements have advantages because of its ability to communicate a big amount of information almost immediately. The implementation of these advantages expressed by visual information is that imagery used in advertisements could be more persuasive than similar information communicated by verbal form. This persuasive potential of visual form can be more powerful in naturalistic situation when consumers have less time to be exposed to an advertisement, or face similar contradiction where it is bit difficult to pay attention towards an object which consumers are asked to respond.

Researches show that visual imagery has some special advantages over verbal information in the context of persuasive imagery in the condition of mental constraint (Mcquarrie et al., 2003a; Hung and Wyer, 2008). There is one exception, previous researches had been focused on the same context but where people had lots of time to process the advertisement (Mcquarrie et al., 2003b).

\subsection{How images create meaning:}

There are three categories of an image: syntax, semantics and pragmatics. These three steps are the way to understand the cognitive process in the viewer's mind created by image. At first, when a viewer approaches an image of advertisement, viewer perceives it with general bricks and forms to build up the total image. Then the viewer understands the signs and tries to interpret the whole image (Morris, 1946). Sometimes it is tough to understand the signs because there are no apparent boundaries between the parts of image. Once a viewer is able to identify the particular element as a sign, then image can be explored (Fiske, 1990): 
I. Syntax, the Esthetical Level (Form): In a formal figure, syntax is the relation between signs. It basically focuses on form and the unit of image's rough material. A viewer is provided a type of hierarchy by the structure and construction of different elements, so that a viewer can understand less important and more important element. A connection is developed between dissimilar elements.

II. Semantics, the referential level (Content): The semantics is about its referred things and the connection between different signs. This is all about the image's content. The signifier and signified are the two components which make sign together. Signifier is the image of sign as seen by viewer and the signified is the concept behind it. This concept is widely common to the members of same language.

III. Pragmatics, the Communicative Level (Interpretation): A viewer's cognitive process is considering the various aspects. A spectator connects the elements together and tries to evaluate it with the help of its perspective. An image is constructed by form and content. Image behaves like a message. Content changes over into argument or statement.

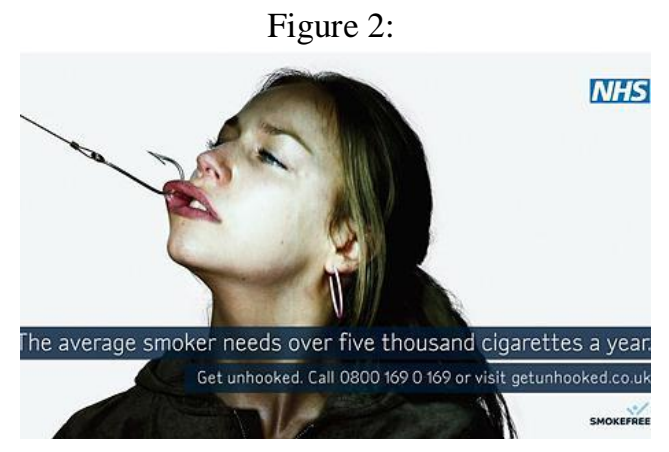

"Get Unhooked": here in this social advertisement, text plays the anchor role on the connotative meaning. Text guides the consumer towards the particular meaning rather than other. In this advertisement, girl's smoking addiction is depicted as a fish get caught.

Williamson (1978) talk about the different objects in an advertisement which connects to particular qualities. For example picture of a girl can represent the youth and beauty. In advertisements, certain objects can be taken granted for some particular qualities. The composition of different objects is important that how the elements are framed together.

Figure 3:

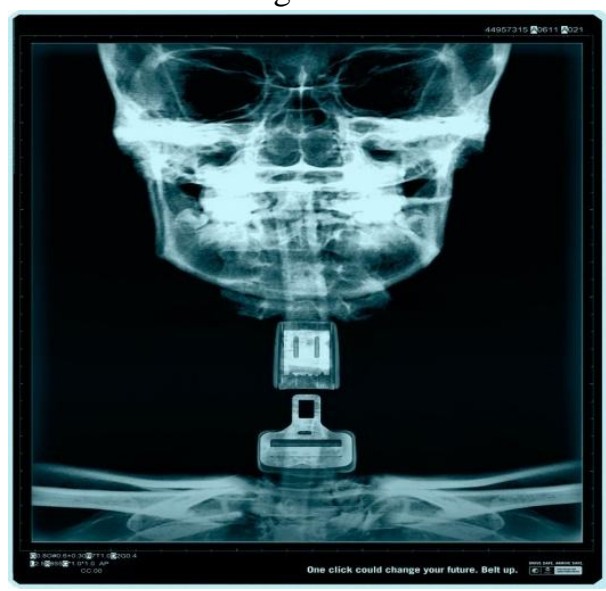

"Belt Up": One can save his/her life using safety belt while driving. The image is an example of radiogram. The belt depicts the connection in neck. 'A safety belt can save a life in a car accident and keep you away of being paralyzed.

\subsection{Influences of Images in Social Advertisements}

In a social campaigning, an advertisement tries to influence on an individual level with the help of different media. Social campaigns try to influence a consumer and focus on different aspects of the cognitive system of human beings, which are as follows:

- KNOWLEDGE- The transmitting new knowledge, expand or differentiate from already existed knowledge and then swapping or changing the old or incorrect knowledge. Example can be seen in Appendix 1 (advertisement 11), which illustrates the issue that a big number of people are dying in the world because of bad drinking water. This image shows the connection between the main cause and the world's most horrific 
incidents. This social campaign works on knowledge and presents the fact that 2000 times more people than in illustrated incidents die because of having bad drinking water. Viewer can get an idea about number of people dying each year due to bad drinking water.

- ATTITUDE- Building up or reinforcement of present attitudes or replacement of unhealthy attitude with desired attitude. Attitude can be seen in the example image (figure 4 given below).

- BEHAVIOUR- Change in behavior or reinforcement of current behavior. Example of behaviour is the advertisement 12 (in Appendix 1), which depicts light bulb but the bulb is made by greenery which shows that the viewer can be more environment-friendly.

A campaign focuses on one of these three elements or combines various concepts into single message. In the context of knowledge, information is there for audience. Direct influence may not be constructed on attitude or behavior.

\section{Figure 4:}

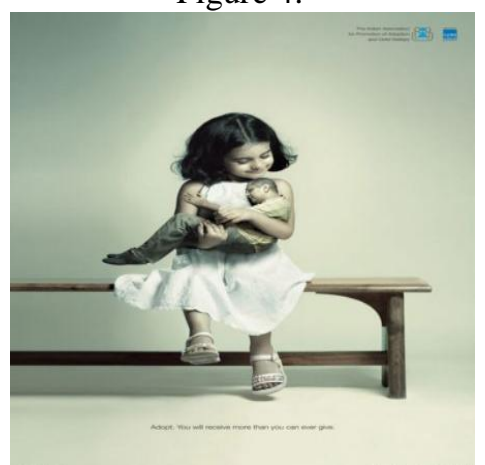

"Adopt": Image shows a positive reinforcement of attitude by showing a child adoption. The child is exaggerated and keeps the adopter closer in her arms. "Adopt. You will receive more than you can ever give".

\subsection{Impact on Attitude towards advertisements}

Lutz (1985: p.53) defines attitude towards advertising as "a learned predisposition to respond in the consistently favorable or unfavorable manner to advertising in general". An attitude is basically an imaginary construction that signifies an individual's personal perception as like or dislike. Attitudes are in different modes such as negative, positive or neutral views directing to an 'attitude object': i.e. a person, event or a behavior. A strong attitude is quite defiant to change.

(Perloff, 2003) To lessen the dissonance between real behavior and the existing attitudes People often reorganize their attitudes to a specific behavior. The theory of cognitive dissonance by Leon Festinger (1957) (Figure 1) states that contradicting cognitions work as a driving force, which makes the mind to be compelled to obtain or invent new beliefs or thoughts, or to the modifications of existing beliefs, so as to the reduction of the amount of dissonance (conflict) between cognitions. If we take somebody as an example who decides to quit smoking and he or she is also convinced about the negative effects of smoking, even than keeps on with it, this is a cognitive dissonance, which develops between what you think, your attitude ('Smoking is bad for me') and the actual behaviour is still smoking. To reduce this dissonance you need to adapt your behaviour to your attitude, stopping with smoking, or adapt your beliefs and attitudes ('I love smoking and I will stop after some time') to your behaviour. On the right side you see some examples of Anti-smoking campaigns which try to stimulate a dissonance in the viewer by arguing, when smoking, you smoke up yourself. The images on the bottom depict a lighter and two cigarettes as weapon which shows the statement that smoking is killing. Bullet is filled into a cigarette. This bullet is showing the fact that if you lit up the cigarette, it can kill you. In other advertisement 14 is example which shows the lighter is aiming at the viewer and which means, smoking kill others. Burning cigarette is held into fingers and the shadow depicts the gun (advertisements 13, 14 in appendix 1), although the lighter is not the object causing the death.

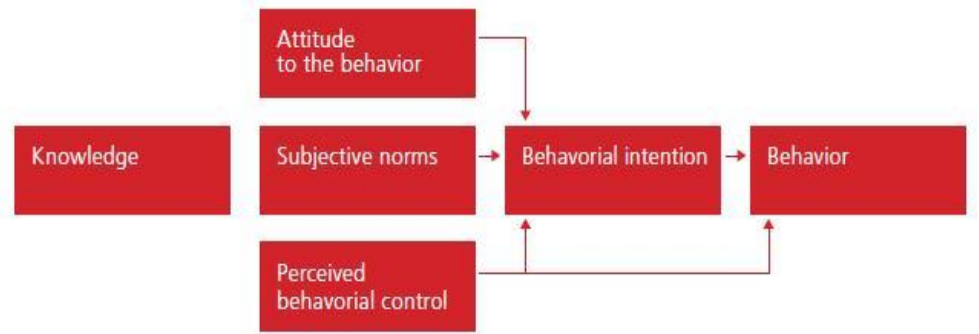

3.6 Various Social Campaign Approaches 
In general there could be three different concepts for the development of social campaigns: cognitive, affective, and behavioral approach (Ohme, 2000).

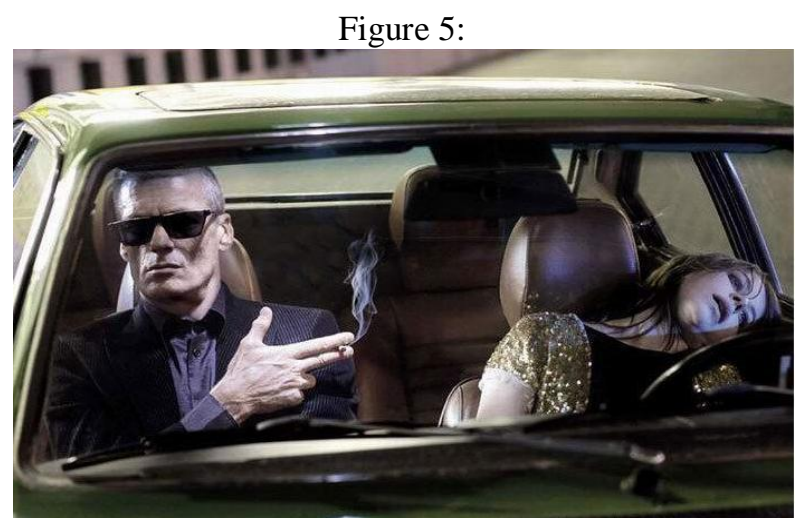

People can get killed by passive smoking. Smoking hand creates the gun towards the dead girl in opposite side. As a smoker you kill people.

\subsection{Information Processing}

After the presentation of a message the information first need to be processed by the audience. In the past and even in present some of the communication professionals tend to make use of basic linear models of persuasion. One of them is AIDA-reaction model (Strong, 1925), which particularly is used in the marketing context (Figure 7). First you draw attention, then the interest is created, the target group develops a wish and lastly they go over to action. The weak point of this theory is its simplification as well as the fact, that it does not take other mediating variables into the consideration.

FIGURE 7:

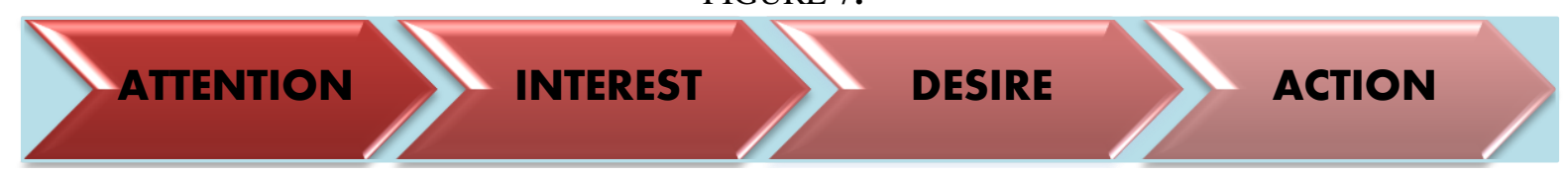

Source: AIDA MODEL (Kotler, 2004)

\subsection{Introduction:}

\section{Research Methodology}

This Chapter explains the methods of conducting research, primary and secondary data collection through qualitative research methods and various techniques. A research methodology consists of different methods, processes and tools which are used in practicing the research in any research field (Nunamaker, Chen and Purdin, 1991). It also explains the reason, why a certain methodology was adopted and other methods were discarded. Advantages and disadvantages in each research method were examined and the basis of aim and objectives of research. Research methods provide enormous knowledge and new theories (Collis and Hussey, 2009)

"Research methodology is a systematic collection and interpretation of information with a clear purpose, to find things out" (Saunders et al., 2007: p.612).

\subsection{Perspective of Research} research

Saunders et al. (2007) has categorized the research purpose as descriptive, exploratory and explanatory

Descriptive research supposes to portray a precise profile of events, persons or situations. "Descriptive research relies on observation as a means of collecting data. It attempts to examine situations in order to establish what is the norm, that is what can be predicted to happen again under the same circumstances" (Walliman, 2006. p.38). While, studies that set up casual connection between variables can be termed explanatory studies. The prominence here is on studying a situation in order to clarifying the relationship amongst variables. Exploratory study is useful when a researcher wishes to simplify his understanding of a problem. Here researcher intent to investigate, how social campaigns' visual make their place in consumers' mind and consumers' perception and attitude towards the visual persuasion of social campaign advertisements. In view of the fact that the question is exploratory, thus researcher has used exploratory study as a nature of research study. 


\subsection{Research process}

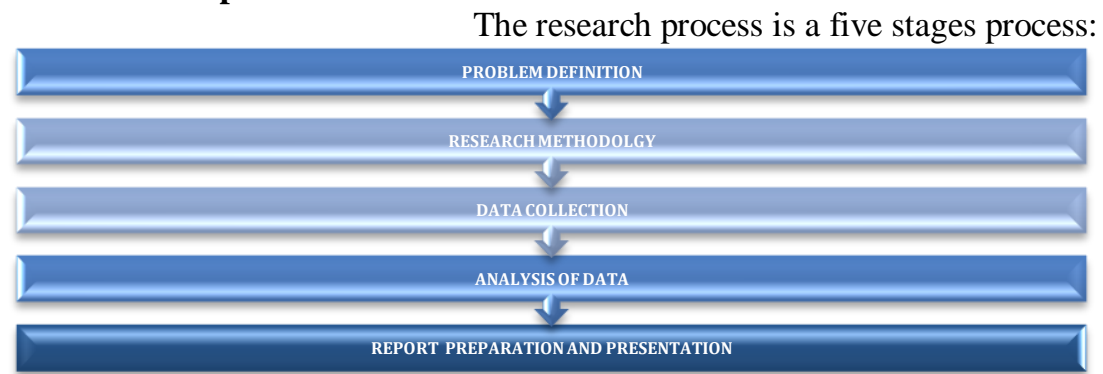

FIGURE 9: THE RESEARCH PROCESS;

SOURCE: ADAPTED AFTER CRESWELL (2003: P.138)

As this study analyses the social advertisement imagery's impact on the perception and attitude of consumer, four research questions in form of propositions were developed:

P1: The overall attitude and perception of the targeted audience towards images in social advertising campaigns is positive.

P2: Visuals always conveys the social message more effectively with a verbal notification or tagline in a social advertisement.

P3: Advertisements with social cause doesn't often influence directly action taking intension towards the social issue.

P4: Males and females have different perception and attitude towards different social campaigning advertisement.

\subsection{Introduction}

\section{Data Analysis \& Findings}

This chapter reflects the analysis of data collected by using qualitative research method. Objectives of research are fulfilled by using focus group method. Focus groups and semi-structured open-ended questionnaire are used in order to conduct this research with randomly selected twelve participants divided into six male and six female. The study to explores and explains the consumer attitude and perception towards the images of social campaign advertising in the context of different social causes. Two focus groups were conducted, both of them having three male and three female participants each. Data is presented in a manner that information can be easily interpreted. Findings have been fully examined and discussed and a conclusion will be drawn in respect to the aim of this thesis. The findings are divided into perception towards images of social advertising, emotions towards images of social advertising, attitude towards social advertising and male \& female attitude towards images of social advertising. The social campaign advertisements are included, justified and described in a table in Appendix 2.

\subsection{Perception towards social advertising}

As a result of evaluating picture 1 (Appendix 3), the study revealed that consumers respond to different social campaigns in different ways. In this context, there is an argument made by La Tour (1990) that men are more likely to approve of social advertisements containing different shock elements like nudity, violence or weird situations because nudity can be sexually attractive, violence can be action and weirdness can be something different for them because these elements are very subjective. This study seeks to explore this issue in greater depth. Table (3) summarizes different positive or negative views on social advertisements expressed by the subjects. These all views given are subjects' personal views about social advertising images.

For social "advertisement" 1 (picture 1), all respondents agreed that it was really vulgar and unworthy. They felt nudity was exaggerated and more focused on nude girl. It provoked similar feeling in male and female respondents. There was a response with question that:

"Why is the girl nude and having no cigarette while it is an anti-smoking advertisement?" and expressed a loud attitude for the type of nudity used. Debi (female) even said:

"I don't understand why the girl is nude while the advertisement contains a social message. Focus should be more on cause. Nudity is diverting the focus from anti-smoking message. It is shocking for me."

But another female Sana answered her in a different way with a different context. She expressed her personal view for this advertisement and said:

"although I don't see the nudity relevant to the cause of advertisement and the visual is not enough catchy in the context of social cause [persona appraisal], I see this advertisement bit effective because there wouldn't be any space of showing burning internal organs if there was no nudity, which indeed catches my eyes [effectiveness]. The model is quite sexy [personal appraisal] and the fact that model is in the gesture of smoking 
which looks like she is smoking, you cannot miss the message portrayed and this makes it a good social advertisement [effectiveness]."

For "advertisement 2 (picture 2, appendix 3)" all respondents felt it was an impressive advertisement. Some of them felt it contains a bit gore and shock element but it is very convincing in the context of delivering the social cause. Female respondents also expressed the similar views towards the advertisement with the views such as shocking, brutal, convincing and informative. There were mixed views towards this advertisement. At the first instance advertisement felt like brutal, gore and unoriginal but as participants are exposed to the advertisement, and they understood it and see it as an excellent piece of advertising. There was a small difference between the opinions of male and female respondents, as male respondents liked the advertisement from the first instance and did not expressed any negative views for this advertisement compared to female respondents, who felt uncomfortable initially with this advertisement. At the end of the discussion almost all participants agreed that this advertisement was smartly done. Johanna

\begin{tabular}{||c|c|c|c|c||c|c|c|c|c||}
\hline \hline \multicolumn{9}{|c||}{ FEMALE } & \multicolumn{5}{c||}{ MALE } \\
\hline Ad 1 & Ad 2 & Ad 3 & Ad 4 & Ad 5 & Ad 1 & Ad 2 & Ad 3 & Ad 4 & Ad 5 \\
\hline Nudity & Brutal & Horrifying & Crime & Cute & Sexy & Informative & Interesting & Striking & Weird \\
\hline $\begin{array}{c}\text { Eye- } \\
\text { Catchy }\end{array}$ & Horrible & Creative & Murder & Nice & Nudity & $\begin{array}{c}\text { Eye- } \\
\text { catching }\end{array}$ & Excellent & Meaningful & Beautiful \\
\hline Flashy & Shock & Scary & $\begin{array}{c}\text { Movie- } \\
\text { scene }\end{array}$ & Subtle & Vulgar & Scary & Confusing & $\begin{array}{c}\text { Thought- } \\
\text { provoking }\end{array}$ & Sensitive \\
\hline Irrelevant & Relevant & Excellent & Vague & Beautiful & Hot & Powerful & Horrific & Depressing & Emotional \\
\hline vague & Informative & Fatal & Dead & Cute & $\begin{array}{c}\text { Over- } \\
\text { done }\end{array}$ & Effective & Impactful & Gothic & Sensible \\
\hline Nudity & Painful & Dark & Interesting & Lovely & Irrelevant & Unrealistic & Effective & Bold & Adorable \\
\hline
\end{tabular}

Results indicate the perception towards social campaign advertisements differed quite significantly between male and female respondents. Both male and female evaluate the depiction of different elements in an image more favourably (Reichert, 2002). When analyzing the sexual content in social advertisement, it appears that female evaluate nudity more favourably than male evaluate it. Apart from nudity females are more sensitive towards the content of image whether it is a gore, shocking elements or emotional elements. Males are more sensitive towards the cause behind the social advertising image. This study revealed that men perception of social advertising used in Image one and Image 4 is not positively impressing; while the female respondents found Image 2 and Image 3 (picture 2 and 3 in appendix 3) more shocking. Overall both male and female respondents found image 2 and image 5 impacting positively.

Data analysis suggests that female respondents have a more positive perception towards the images compare to male respondents. However, when analyzing the full transcripts of respondent groups, the female respondents were clearly less impressed by many of the social advertisements featured. Because according to them, advertisements were quite complex and indirect towards the cause of advertising. It took them some time to explore the cause in some images. "I feel confusing when I look this picture. I don't really get the message, what is the skull trying to convey [Birgit, female; discussing about the Image 3 (picture 3 in appendix 3)]. Clearly, females respondents struggled a bit to find out the basic cause of the image. Male respondents were quite impressed with the way image were created and they were not affected by the content which was used to create the social advertisement.

\section{Conclusion}

This study was designed to describe and explore perception and attitudes towards images in social campaigning advertisements in previously overlooked framework. Researcher conducted his research taking and aspect into consideration that the existing literature has not investigated.

Because there were not much previous researches have done, especially consumer attitude including research on male and female attitude and perception. Social advertisers feels the dilemma whether their advertisement will be noticed or not.

This study makes contributions to academic research on images in social campaigning advertisements in the key areas of perception and attitude towards social advertising, attention and interest, congruence and gendered study.

\subsection{Perception towards Social Advertising}

An important contribution of this research is in building insights in to the understanding of consumers' perception towards images in social advertising campaign. In support with P1, there is powerful evidence to suggest that the overall perception of targeted audience towards image in social advertising campaigns is positive.

It is important to remember as well that differences in opinion still existed inside the groups, as extreme negative and positive views were expressed on the issue between the female and the male respondents. All the way through the study, the gender of respondents has seen as a evidence to be an important determining 
factor of evaluations and interpretations of different elements in social advertising image. Regarding study specific to respondents' gender difference and different elements, a consistent finding is that both males and female evaluate the depiction of image very subjectively. Data analysis explained that although respondents evaluate the image more subjectively, it appears that female evaluate images with a similar way but male respondents gave random views even they were in a group. This was specifically proved when contrasting and comparing advertisement one and three. There was a clear perception that nudity and complexity was unnecessary. This was primarily because of the respondents' feeling that the connection between 'nudity and smoking' and ' $\mathrm{x}$-ray and belt' was just created by advertisers. Still the female respondents were more positive towards expressing the views when analyzing the advertisement three, which depicted a skull $\mathrm{x}$-ray and had negative views while assessing the advertisement one. While male respondents were bit more towards advertisement one which depicted nude model, they found it interesting. This analysis achieves the objective 1 and objective 3 .

\subsection{Attitude, Interest and Attention}

Another contribution of this research focuses on the provision of main evidence regarding existing research theories which claims that shock imagery and sexual contents in social advertisements is noticed and afterward remembered. Reichert (2002: p.252) states that "sexual imagery attracts a viewer's attention and processing resources, leaving few resources available for processing of other ad information" and as a result cause remains unnoticed sometimes and doesn't get processed with same intensity.

There is strong evidence that shocking elements attracts attention and interest of consumers. As a result of analysis of findings, the researcher came to the conclusion that sexual and shocking content theme are the most effective in attracting respondents' eye in terms of attention and interest. Although, there was no clear connection between cause and the elements used in advertisement two: shock element of image did not deviate respondents from the main cause of the social advertisement. Most participants remembered the cause behind social advertisement and they admitted about advertisement that it is a clever composition of elements in advertising because of the justification of its tagline through imagery of advertisement.

The finding of research also show that respondents were more engaging, interesting and involving once they started to get the logic behind the social advertising images. The social advertisements used in portfolio were enough interesting but perhaps couldn't be as effective as with more shocking themes. This aspect was stated out by Saan (male) when he shared his point of view about the elements in social advertisements. Saan (male): "advertisers should keep shocking elements as more as possible because it is very eye-catching and noticeable and there should be some humor as these images felt like serious deal". The finding of this section achieves the objective 2 .

\subsection{Congruence}

This research contributes in building insights into significance of "congruence". Extant theories claim that consumers are more accepting different elements such as nudity and shock element in social advertising when they can see a clear congruence between the content of image and the cause behind social advertisement (Tissier-Desborodes, 2006). Research findings are in accordance with these theories, in that, consumer distinguish a clear link between the social issue advertised and content in image, consumers are more likely to interpret the social advertisement favourably. But, interestingly, respondents felt that their attention can be better captured when no much congruence can be seen between the social issue and the content of image used. This is because it builds a controversial feeling; such social advertisements establish the consumer to study it, remember it and discuss it with friends, the social cause and the content used in advertisement.

This study also presents observed support and suggestion that the viewer seeks out congruencies not only with the social cause and content but also with the message. For example in the advertisement five, respondents note that the advertisement was not containing much shocking elements and the contents present in the social advertisement represent the social cause somehow.

\section{Limitations}

The major limitation of this research is its scale of respondents. Due to time and resource restrictions, this study offers a small sample of a total of 12 subjects (6 per sample focus group). The sample is not necessarily representative of wide range of consumers. Therefore the analyzed finding, analysis and implications of this research should be generalized and implied with caution.

The focus groups were moderated by a male researcher which might have affected the respondents' responses and views. Some respondents may have felt a discomfort and been embarrassed about discussing some sexual content or shocking contents in social advertising. Future research studies may like to consider a larger number of respondents using both female and male moderators, or using quantitative methods that allows an anonymous participation by participants. 
Many aspects emerged from analyzing the data which are clearly significant in understanding the consumers' attitudes and perception towards image contents in social advertising campaigns. Nevertheless, because of the time restriction, these aspects could not be explored in such a greater depth within this research study. Future research work may construct on these findings with a larger scale study.

It will be interesting to examine the overall perceived attitude against the real action further, to make sure whether perceived and real perception differs. Investigation on different consumers' culture and population can provide an interesting topic for further research studies. Different age groups and consumer population have their different influences, thus it would be interesting to contrast and compare the effect of images on consumers' attitude and perception in social advertisements.

\section{References}

Bloom, P. N., Novelli W. D., 1981. Problems and challenges in social marketing. J Mark, 45(2), pp.79-88.

Kotler, P., 2005. Social marketing in the 21st century. Thousand Oaks, CA: Sage Publications.

Kotler, P., and Armstrong, G., 1989. Principles of Marketing. $4^{\text {th }}$ ed. Englewood Cliffs, NJ: Prentice Hall.

[4] LUTZ, R.J., 1985. Affective and Cognitive Antecedents of Attitude towards the Ad: A Conceptual Framework. Psychological Processes and Advertising Effects: Theory, Research and Applications, Linda Allowed and Andrew Mitchell, eds, Hillsdale, NJ.

[5] Kotler, P., and Zaltman, G., 1971. Social Marketing: An Approach to Planned Social Change. Journal of Marketing, 35 (July), pp. 3 12.

[6] PERLOFF, R.M., 2003. The Dynamics of Persuasion: Communication and attitudes in the $21^{\text {st }}$ Century (2e druk), Mahwah: Erlbaum.

[7] Barry, A. M., 1997. Visual Intelligence: Perception, Image, and Manipulation in Visual Communication. Albany:State University of New York.

[8] Barry, A. M., 2005. Perception Theory (Chapter 3). In Moriarty Smith, Barbatsis, Kennely, ed(s), Handbook of Visual Communication (Mahwah, NJ:Lawrence Earlbaum, Associates.

[9] PHILLIPS, B.J., and McQUARRIE, E.F., 2002. The Development, Change, and Transformation of Rhetorical Style in Magazine Advertisements 1954-1999. Journal of Advertising, 31(4), pp. 1-13.

[10] Schroeder, J. E., 2002. Visual Consumption. New York, NY:Routledge.

[11] Childers, T. L. and Yang Jiang, 2008. Neurobiological perspectives on the nature of visual and verbal processes. Journal of Consumer Psychology, 18(4), pp. 264-269.

[12] Hung, I. W., and Wyer, R.S., 2008. The impact of implicit theories on responses to problem-solving print advertisements. Journal of Consumer Psychology, 18(2008), pp. 223-235.

[13] McQuarrie et. al, 2003a. The Contribution of Semiotic and Rhetorical Perspectives to the Explanation of Visual Persuasion in Advertising. In LM Scott \& Rajeev Batra, ed(s), Persuasive Imagery: A Consumer Response Perspective(191-222), Mahwah, NJ:Lawrence Earlbaum Associates, Inc.

[14] McQuarrie et. Al, 2003b. Visual and Verbal Rhetorical Figures under Directed Processing versus Incidental Exposure to Advertising. Journal of Consumer Research, 29(4), pp. 579-587.

[15] Morris, C.W., 1946. Signs, Language and Behavior, New York: Prentice-Hall.

[16] Fiske, J., 1990. Introduction to Communication Studies, London: Routledge.

[17] Williamson, J.E., 1978. Decoding Advertisements: Ideology and Meaning in Advertising, London: Marion Boyars.

[18] NUNAMAKER, J.Chen, M. and PURDIN, T., 1991. Systems Development in Information Systems Research. Journal of Management Information Systems, 7, pp.89-1056.

[19] SAUNDERS. ET AL., 2007. Research Methods for Business Students. $4^{\text {th }}$ ed. London. Pearson Education.

[20] WILLIMAN, N., 2006. Social Research Methods. $2^{\text {nd }}$ ed. London. Sage Publications.

[21] CRESWELL, J., 2003. Research design: Qualitative, Quantitative and Mixed Methods Approaches. $2^{\text {nd }}$ ed., London: Sage publications.

[22] Reichert, T., and Lambiase, J., 2002. Sex in Advertising: Perspectives on the Erotic Appeal, London: Lawrence Erlbaum Associates, Inc.

\section{Bibliography}

Ajzen, I., 1991. The theory of Planned Behaviour. Organizational Behaviour and Human Decision Processes, 50, pp. 179-211. Barthes, R., 1977. Rhetoric of Image, In Barthes,R., Image, Music, Text, Glasgow: Fontana/Collins. BELL, J., 2005. Doing your Research Project. $4^{\text {th }}$ ed. Berkshire. Open University Press.

BLAXTER. L., HUGHES. C., and TIGHT. M., 2006. How to Research. $3^{\text {rd }}$ ed. Berkshire. McGraw Hill.

BLAXTER. L., HUGHES. C., and TIGHT. M., 2006. How to Research. $3^{\text {rd }}$ ed. Berkshire. McGraw Hill. BLUMBERG, C. and SCHINDLER, 2006. Business Research Methods. $1^{\text {st }}$ ed. McGraw-Hill/Irwin.

CATHERINE, D., 2007. Practical Guide to Research Methods, A User-Friendly Manual for Mastering Research Techniques and Projects. $2^{\text {nd }}$ ed. How to Books.

DONOHUE, R., COOPER, B., and THARENOU, P., 2007. Management Research Methods. New York. Cambridge University Press. Franks, D., 2003. The Neuroscience of Emotions. In JE Stets \& JH Turner, ed(s), Handbook of the Sociology of Emotions(38-65), New York:Springer Science + Business Media, LLC.

GHAURI, P.N. and GRONHAUG, K., 2005. Research Methods in Business Studies: A Practical Guide. New York: Prentice Hall.

KENNY, K., and SCOTT, L., 2003. A Review of the Visual Rhetoric Literature. In LM Scott \& Rajeeb Batra, ed(s), Persuasive iagery: A Consumer Response Prespective (17-55), Mahwah, NJ: Lawrence Earlbaum Associates, Inc.

KENT, P., 2007. Marketing research: approaches, methods and applications in Europe. London: Thompson Learning.

KERZNER. H., 2009. A system approach to planning, scheduling and controlling. Project Management. $10^{\text {th }}$ ed. Wiley.

Kotler, P., 2004. Marketing Management. $11^{\text {th }}$ ed. Pearson Education.

Kress, G., and Leeuwen, T., 1996. Reading Images: The Grammar of Visual Design, London: Routledge.

Krueger, R. A., 1994. Focus Group: A Practical Guide For Applied Research. Thousand Oaks CA: Sage Publications.

Krueger, R.A., and Casey, M.A., 2000. Focus Groups: A Practical Guide for Applied Researc. $3^{\text {rd }}$ ed. Thousand Oaks, CA: Sage Publication.

KUMAR, AAKER, and DAY, 1999. Research Methods: A Review. Wishwa Prakashan, India.

Merton, R., Fiske, M., and Kendall, P., 1990. The Focused Interview. New York: The Free Press.

Mieke B., and Norman B., 1991. Semiotics and Art History. The Art Bulletin, LXXIII, 2(1991), pp. 174-208. 
Consumer Perception and Attitude towards the Visual Elements in Social Campaign Advertisement

[21]

[22]

[23]

[24]

[25]

Mitchell, W. J. T., 1986. Iconology, Chicago, I11, University of Chicago Press

Petty, R.E., and Cacioppo, J. T., 1986. Communication and Persuasion. Central and peripheral Routes to Attitude Change, New York: Springer-Verlag.

RICHINS, M.L., 1991. Social Comparison and the Idealized Images of Advertising. Journal of Consumer Research, 18, pp. 71-83.

Shepard, R., 1990. Mind Sights: Original Visual Illusions, Ambiguities and Other Anomalies. San Francisco: W.H. Freeman.

Annexures

\section{Semi structured questionnaire}

Consumers' perception and attitude towards the visuals in advertisements of social campaigns.

Moderator's introduction:

We are here today to talk about the visual persuasion created by the images in social campaign advertisements and consumers' perception and attitude towards social advertising. The purpose is to get your perceptions on advertisements with social cause and whether and how social advertisements create a specific perception, attitude and emotion in consumers' mind specifically in gender bases (what is the perception of male and female distinguish). I would like you to feel comfortable saying what you really think and how you really feel.

1. General information-

a) What social messages in advertising you are aware of in general?

b) According to you, which of the following examples are most effective visual imagery source in terms of conveying the message? Why?

2. Understanding-

a) At the very first instance, is the message of the visual used, clear in print advertisements? How?

b) Should social campaigns advertisements focus more on its visuals or its verbal? Suggest with reasoning.

3. Emotions-

a) How do you feel looking at each of these pictures?

b) How do you feel about the social issues promoted through these five advertisements in general?

4. Perception-

a) Which of the images is the most impressive? Why?

b) Do you like the visual used in presented social advertisement? If you could, what would you like to change in it?

5. Attitude-

a) Do visual images used in the social advertising campaigns, directly persuades you or it just creates the attitude or it only creates the interest towards the issue? Explain.

b) Do these social advertisements make you interested in the message sent across? Does it grab your attention?

\begin{tabular}{|c|c|c|c|c|c|}
\hline $\begin{array}{l}\text { PICTURE } \\
\text { No. }\end{array}$ & $\begin{array}{l}\text { IMAGE } \\
\text { CONTENT }\end{array}$ & DESCRIPTION & CAUSE & $\begin{array}{l}\text { ADVERTISMIENT } \\
\text { DESCRIPTION }\end{array}$ & ADVERTISMINT \\
\hline Ad. 1 & Nudity & $\begin{array}{l}\text { Unclothed } \\
\text { E Side shot } \\
\text { E Shower scenes } \\
\text { E Revealing } \\
\text { E Burning internal organs }\end{array}$ & $\begin{array}{l}\text { Cigarettes } \\
\text { smoke you. }\end{array}$ & $\begin{array}{l}\text { Naked women body. } \\
\text { There is a girl, who has kept her } \\
\text { hand on her mouth depictedas she } \\
\text { is smoking. As she is smoking her } \\
\text { internal organs are burning like } \\
\text { cigarette tip. }\end{array}$ & E \\
\hline Ad. 2 & Gore, shock & $\begin{array}{l}\text { Cheek hooked } \\
\text { Enowledge } \\
\text { E gore }\end{array}$ & $\begin{array}{l}\text { Get unhooked } \\
\text { from smoking. }\end{array}$ & $\begin{array}{l}\text { Shock image. } \\
\text { A girl is hooked by her cheek. } \\
\text { Hook is pulling her towards itself. } \\
\text { This is looking like a gore and } \\
\text { verbal tagline supporting it with } \\
\text { knowledge. }\end{array}$ & \\
\hline Ad. 3 & Scary (skull) & $\begin{array}{ll} & \text { Scary } \\
\text { E Skull } x \text {-ray } \\
\text { Eelt }\end{array}$ & $\begin{array}{l}\text { Belt up your } \\
\text { seat-belt. }\end{array}$ & $\begin{array}{l}\text { Scary mes sage. } \\
\text { Skull } x \text {-ray is showing a man skull } \\
\text { having a belt illustrated on the } \\
\text { neck, which shows if you belt up, } \\
\text { you will be safe. If you don't, you } \\
\text { are dead. }\end{array}$ & \\
\hline Ad. 4 & $\begin{array}{l}\text { Action, } \\
\text { shock }\end{array}$ & $\begin{array}{l}\text { Illusion of shooting a girl } \\
\text { by a gun. } \\
\text { Gun shooting action. } \\
\text { Eead girl } \\
\text { E Smoke }\end{array}$ & $\begin{array}{c}\text { Passive } \\
\text { smoking kills } \\
\text { others. }\end{array}$ & $\begin{array}{l}\text { Smoking illustrated like shooting, } \\
\text { A man smoking a cigarette, } \\
\text { depicting like shooting a girl } \\
\text { nearby him. }\end{array}$ & \\
\hline Ad. 5 & $\begin{array}{l}\text { Shock, } \\
\text { beautifulness }\end{array}$ & \begin{tabular}{|ll} 
E & Cuteness \\
Small child \\
(exaggerated) \\
E Man (depicted small) \\
E beautifulness
\end{tabular} & Adopt a child. & $\begin{array}{l}\text { Child hugging a man. } \\
\text { Small child has been illustrated } \\
\text { exaggerated while she is hugging a } \\
\text { man, who adopted her and loving } \\
\text { here. }\end{array}$ & \\
\hline
\end{tabular}

